\title{
COVID-19 Pandemic and Challenges for Dental Education
}

The COVID-19 pandemic has a different impact on everyone. The impact is not only on mortality and morbidity in infected people but also on the mental health of uninfected people. ${ }^{1,2}$ Apart from the health side, other sectors that may also be affected include the industrial sector, tourism, and education. ${ }^{3}$ The COVID-19 pandemic poses enormous challenges to all stakeholders in the educational field such as lecturers, students, and leaders and staff of institutions. ${ }^{1}$ Learning that was previously delivered in-person in the classroom has shifted to an online platform. The trend for all elements in learning today is towards the digital arena. One solution in the world of education is the use of asynchronous learning, which allows learning to be carried out at different times. It gives lecturers the flexibility to prepare learning materials and allow students to adjust to the demands of home and study. This system creates flexibility in learning without compromising competency.

In the field of dentistry, in addition to learning in the classroom to obtain cognitive abilities, learning to achieve psychomotor abilities is also important. This psychomotor ability in dental education can be done through a simulation laboratory and clinical skills training. These aspects are challenging. Several countries have implemented the use of virtual reality (VR) in simulation laboratories to get the sensation of practice on the simulation model. However, this has not yet been fully adapted to all dental education institutions because the facilities owned by the institution still do not fully support this technology. ${ }^{4-6}$ The high risk of transmission through aerosols is a major challenge in dental education based on clinical skills training. ${ }^{7}$ The use of tele-dentistry, an electronic-based dentistry medical consultation facility, is an alternative. ${ }^{8,9}$ This facility can shorten dental treatment visits that have a high risk of transmission. In addition, in emergency dental care and other dental treatments, the use of adequate personal protective equipment (PPE) can reduce the risk of infection transmission.

Finally, dental education innovations in cognitive and psychomotor aspects are urgently needed today in the era of the COVID-19 pandemic to achieve optimal student competencies.

\section{Dr. Agung Sosiawan, drg., M.H., M.Kes. Dean \\ Faculty of Dental Medicine Universitas Airlangga}

\section{REFERENCES}

1. Daniel J. Education and the COVID-19 pandemic. Prospects. 2020 Oct;49(1):91-6.

2. Pfefferbaum B, North CS. Mental health and the COVID-19 pandemic. N Engl J Med. 2020 Aug 6; 383(6):510-2.

3. Khanna RC, Cicinelli MV, Gilbert SS, Honavar SG, Murthy GV. COVID-19 pandemic: lessons learned and future directions. Indian J Ophthalmol. 2020 May; 68(5):703.

4. Chang TY, Hong G, Paganelli C, Phantumvanit P, Chang WJ, Shieh YS, Hsu ML. Innovation of dental education during COVID-19 pandemic. J Dent Sci. 2021 Jan 1; 16(1):15-20.

5. Desai BK. Clinical implications of the COVID-19 pandemic on dental education. J Dent Educ. 2020 May; 84(5):512.

6. Alzahrani SB, Alrusayes AA, Aldossary MS. Impact of COVID-19 pandemic on dental education, research, and students. Int J Health Sci Res. 2020 Jun; 10:207-12.

7. Deery C. The COVID-19 pandemic: implications for dental education. Evidence-based Dentistry. 2020 Jun; 21(2):46-7.

8. Machado RA, Bonan PR, Perez DE, MARTELLI H. COVID-19 pandemic and the impact on dental education: discussing current and future perspectives. Braz Oral Res. 2020 Jun 29;34.

9. Machado RA, Souza NL, Oliveira RM, Martelli Júnior H, Bonan PR. Social media and telemedicine for oral diagnosis and counselling in the COVID-19 era. Oral Oncol. 2020 Jun; 105:104685. 